\title{
Alain Dierkens, Frédéric Gugelot, Fabrice Preyat, Cécile Vanderpelen-Diagre, (éds.), La croix et la bannière. L'écrivain catholique en francophonie (XVII XXI ${ }^{e}$ siècles)
}

Bruxelles, Éditions de l'Université de Bruxelles, 2007, 234 p.

Paul Aron

\section{OpenEdition}

\section{Journals}

Édition électronique

URL : http://journals.openedition.org/assr/15183

DOI : $10.4000 /$ assr. 15183

ISSN : $1777-5825$

\section{Éditeur}

Éditions de l'EHESS

Édition imprimée

Date de publication : 1 juin 2008

Pagination : 191-321

ISBN : 978-2-7132-2190-3

ISSN : 0335-5985

\section{Référence électronique}

Paul Aron, «Alain Dierkens, Frédéric Gugelot, Fabrice Preyat, Cécile Vanderpelen-Diagre, (éds.), La croix et la bannière. L'écrivain catholique en francophonie (xvI ${ }^{e}-\left.x x\right|^{e}$ siècles) ", Archives de sciences sociales des religions [En ligne], 142 I avril-juin 2008, document 142-23, mis en ligne le 25 novembre 2008, consulté le 21 septembre 2020. URL : http://journals.openedition.org/assr/15183 ; DOI : https://doi.org/ $10.4000 /$ assr. 15183

Ce document a été généré automatiquement le 21 septembre 2020.

(c) Archives de sciences sociales des religions 


\section{Alain Dierkens, Frédéric Gugelot, Fabrice Preyat, Cécile Vanderpelen- Diagre, (éds.), La croix et la bannière. L'écrivain catholique en francophonie (XVII ${ }^{e}$ XXI ${ }^{e}$ siècles)}

Bruxelles, Éditions de l'Université de Bruxelles, 2007, 234 p.

Paul Aron

1 L'expression « la croix et la bannière » renvoie aux processions religieuses $\mathrm{du} \mathrm{xv}^{\mathrm{e}}$ siècle où l'on voyait défiler, dans une confusion soigneusement organisée, les emblèmes rivaux des paroisses et des confréries. Un peu vieillie, elle s'emploie encore pour désigner une situation compliquée qu'il s'agit de démêler avec patience. De fait, deux constats sont à l'origine de l'ouvrage collectif que publient les éditions de l'Université de Bruxelles. Le premier insiste sur la diversité des opinions que subsume l'adjectif « catholique »: les institutions et les personnalités qui le composent ont des intérêts souvent divergents et les luttes de définition et de légitimité y sont constantes. Le second fait apparaître qu'un catholique qui écrit n'est pas nécessairement un écrivain catholique, et inversement, qu'un écrivain catholique n'est pas automatiquement consacré comme un vrai écrivain. Ces constats montrent toute l'importance de la mise en contexte des écrits qui seront commentés : les mots "catholique » et "écrivain » sont l'objet de nombreux débats et leur sens est toujours relatif à ces débats.

2 Les études ici rassemblées (et éditées avec beaucoup de soin) concernent principalement l'Ancien Régime, la fin du xIX siècle et la période contemporaine. Elles prennent en compte le domaine français, mais aussi, quoique plus marginalement, les mondes catholiques belge, suisse et canadien-français. Cette double extension rend la synthèse difficile, même si la plupart des contributions réussissent à lier les études de cas et la problématique générale. On peut néanmoins mettre en évidence quelques idées forces de l'ouvrage, à l'instar des éditeurs qui s'y essayent dans une longue 
introduction intitulée «Modes de vie, représentations et constructions de l'écrivain catholique en francophonie (XVII ${ }^{\mathrm{e}}-\mathrm{XXI} \mathrm{e}^{\mathrm{e}}$ siècles) ».

Le monde catholique et la littérature sont deux institutions de la vie sociale. Elles ont chacune des manières d'être, des codes de comportement, des règles explicites et implicites. Soulignons d'abord, avec Hervé Serry («Dynamiques institutionnelles, engagements individuels et œuvres littéraires, les écrivains catholiques français dans l'entre-deux-guerres »), ce qui les rapproche : une capacité à susciter de l'adhésion, de la vocation, pour un domaine vécu comme transcendant et extérieur aux déterminismes historiques. Historiquement, cette rencontre s'effectue en un lieu d'apprentissage concret : l'école. Très présente au XVII siècle, comme y insistent Volker Kapp, «Des pensées ingénieuses des pères de l'Église à l'Anthologie de la poésie catholique, l'invention oratoire entre rhétorique et théologie ", et, à propos de Fénelon, Fabrice Preyat, "Auctorialité, croyances religieuses et vérité romanesque dans l'apologétique littéraire à l'aube des Lumières ", cette dimension pédagogique s'efface quelque peu ensuite, lorsque l'enseignement échappe à l'Église. Au Québec et, en partie, en Belgique, elle reste néanmoins essentielle, et ce n'est pas un hasard si Cécile Vanderpelen-Diagre, «La reconversion des écrivains catholiques belges francophones dans la deuxième moitié du xx siècle ", et Dorothéa Scholl, " "Ce qu'il faut à notre pays, c'est une littérature franchement, entièrement catholique": la conception d'une littérature canadienne-française nationale et catholique » indiquent que ces pays ont conservé encore au $\mathrm{xx}^{\mathrm{e}}$ siècle une définition de l'écrivain catholique plus vivante, et assez différente, que celle qui se manifeste en France. Ainsi, à l'évidence, l'Ancien Régime offrait une place privilégiée aux gens d'Église, mais, comme le montrent plusieurs contributeurs, l'affrontement de valeurs divergentes n'y est pas moins violent qu'à la période suivante.

4 La rencontre entre catholiques et écrivains se joue aussi sur le terrain matériel de la société du Livre que les uns et les autres commentent et nourrissent. C'est ce que montre Laurent Susini qui réhabilite quelque peu la figure du Père Binet avec lequel Pascal polémique dans les Provinciales. La rhétorique baroque de son Essai des merveilles de nature caractérise en effet une vision métaphorique où les merveilles du monde se manifestent en joyaux d'expression. Tel est le point que rejette clairement Pascal, qui dissocie le savoir expérimental du vide physique de l'énigme théologique du Dieu caché, et qui réserve à chacun des domaines une écriture spécifique. La question des genres littéraires est dès lors constante, parce qu'elle est liée au statut social que l'écrivain catholique entend occuper comme le montre Jacques Le Brun pour le $\mathrm{XVII}^{\mathrm{e}}$ siècle, «Critique ou apologétique : à propos du statut de l'écrivain catholique à l'âge classique ». Le roman est ainsi longtemps objet de méfiance (Fabrice Preyat), mais le statut de la critique est également soumis à tensions, soit par l'autorité qu'elle tente d'acquérir dans le discours social (tel Barbey d'Aurévilly qu'analyse Corinne Bonafoux), soit par l'évolution même de la réflexion du critique (tel Henri Bremond dont Sophie Houdard étudie finement les contradictions). L'expression de la foi passe souvent par d'autres genres (la poésie ou le théâtre), mais même dans le cas des genres musicaux en soi plus enclins à transmettre une émotion instinctive, les compositeurs sont conduits à transmettre leur foi par les moyens "mondains» de leur compétence technique (Béatrice Jakobs, «"Le salut de l'homme surgit justement là où finit le pouvoir dans la souffrance", le drame musical religieux au $\mathrm{xx}^{\mathrm{e}}$ siècle »). Un remarquable exemple des réactions suscitées par les choix linguistiques novateurs d'écrivains engagés dans un 
travail exégétique est celui de la nouvelle traduction de la Bible dirigée par Frédéric Boyer en 2001 (Pierre Lassave, «Les écrivains de la Bible. Nouvelle Traduction »).

À la question toujours brûlante des contenus s'ajoute celle des représentations. Sur le modèle de Chateaubriand, les écrivains missionnaires mettent en place une rhétorique de la confrontation avec le paganisme où un héros affronte une nature souvent hostile et doit démontrer sa capacité d'adaptation à des terrains très variés. André Dupeyrat, qu'évoque Jacques Marx dans une contribution dense qui pourrait être le point de départ d'un passionnant ouvrage, en est un exemple probant («Un enchanteur chrétien chez les Papous : André Dupeyrat et l'écriture missionnaire »). Au Xxe siècle, la figure du prêtre se fait par contre rare, parce qu'elle a considérablement perdu sa capacité à incarner la médiation entre l'Église et les interrogations du citoyen moderne (Frédéric Gugelot, «Le bégaiement du Père Delombre, la figure du prêtre dans la littérature française aujourd'hui »).

Peut-on s'afficher comme écrivain catholique? Comme en témoignent les auteurs d'ouvrages de piété, l'orgueil auctorial n'a jamais été en odeur de sainteté et l'anonymat est une des formes de la retraite du moi dont la vie littéraire connaît de nombreux exemples. Philippe Martin en montre la portée au XvIII ${ }^{\mathrm{e}}$ siècle ( $"$ L'auteur de piété est-il un anonyme?»), même si, au même moment, rappelle Volker Kapp, la poésie religieuse de Louis Racine connaît une gloire comparable à celle des tragédies de son père. La fin du xIX $X^{e}$ siècle est un moment privilégié pour l'émergence d'une figure, l'intellectuel-écrivain catholique, souvent liée à la conversion (Hervé Serry), qu'une enquête contemporaine peine à mettre en évidence. Il faut le sens du placement et de la distinction de Philippe Sollers pour investir bruyamment cette position désuète (Corinne Valasik, "Intellectuels/écrivains catholiques en France actuellement: une désillusion?»). D'un autre côté, le relatif succès des œuvres de Dupeyrat montre que l'orgueil satanique n'émerge pas toujours là où on le voit (chez les Papous par exemple), mais où on ne l'attendait pas, dans la reconnaissance mondaine de l'auteur par exemple.

7 L'enquête prouve qu'il n'y a pas d'esthétique catholique spécifique, mais une série de tensions entre le statut social de la foi, qui s'exprime dans des genres et par des moyens rhétoriques, et la reconnaissance littéraire de pratiques d'écriture voulues ou perçues comme liées au monde catholique. Le point de vue qui est ici adopté nivelle naturellement les valeurs littéraires (Racine père et fils sont mis sur le même plan), mais il donne de la densité à des débats oubliés et de la profondeur à la perspective historique. C'est dire combien il offre d'intérêt dans une période où, plus que jamais, les questions de l'identité et de la croyance sont d'actualité. 